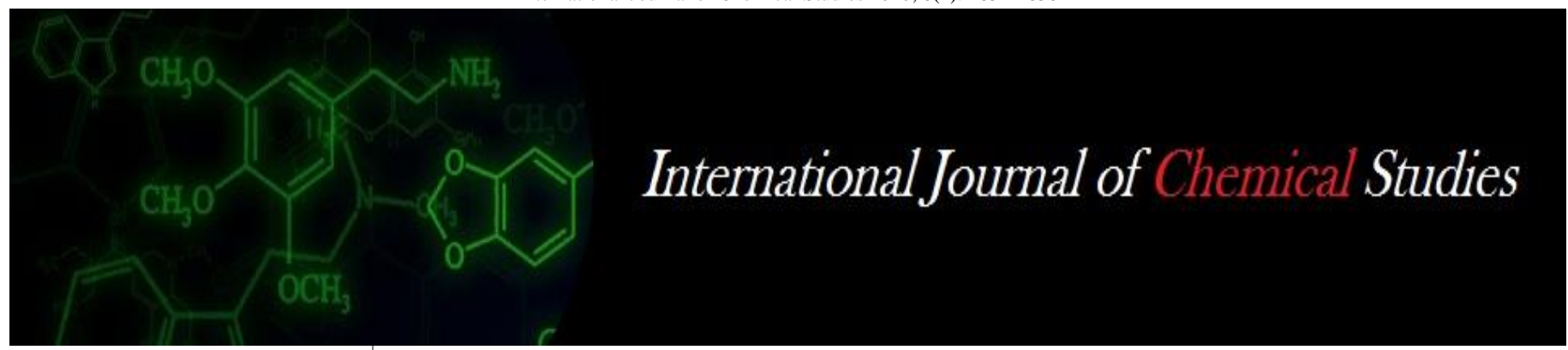

P-ISSN: 2349-8528

E-ISSN: 2321-4902

www.chemijournal.com

IJCS 2020; 8(4): 2854-2858

(C) 2020 IJCS

Received: 19-05-2020

Accepted: 21-06-2020

\section{Jashandeep Kaur}

Department of Food Science \&

Technology, Punjab Agricultural

University, Ludhiana, Punjab,

India

\section{Baljit Singh}

Department of Food Science \&

Technology, Punjab Agricultural

University, Ludhiana, Punjab,

India

\section{Arashdeep Singh}

Department of Food Science \&

Technology, Punjab Agricultura

University, Ludhiana, Punjab,

India

\section{Savita Sharma}

Department of Food Science \& Technology, Punjab Agricultura University, Ludhiana, Punjab, India
Corresponding Author: Jashandeep Kaur

Department of Food Science \& Technology, Punjab Agricultural University, Ludhiana, Punjab, India

\section{Geometric, physical and functional properties of selected pulses and millets for the formulation of complementary food products}

\author{
Jashandeep Kaur, Baljit Singh, Arashdeep Singh and Savita Sharma
}

DOI: https://doi.org/10.22271/chemi.2020.v8.i4ah.10079

\begin{abstract}
Growing concern about eating healthy nutritious foods have shifted focus towards millets and pulses. Formulation of a new food product requires basic information about the raw materials. So the present investigation deals with the analysis of engineering, physico-chemical, functional and pasting properties of pearl millet (PCB-164), sorghum (2077 B line), mungbean (SML-832) and chickpea (PBG-7). Basic information on these properties will open doors for other researches, utilizing this to formulate advanced food products.
\end{abstract}

Keywords: Millets, pulses, physical, engineering, functional, properties

\section{Introduction}

Food processing demands newer food products with today's required characteristics as per the demand of consumers such as gluten free products, low glycemic foods, functional foods etc. Consumers have become highly interested, not only in buying tasty and convenient food products but with a good nutritional profile. Moreover millets could be an alternative in solving the malnutrition and food insecurity crisis in India and many other countries. Millets are highly nutritious easy digestible grains, which are non-glutinous as well as non-acid forming. Generally millets comprises of $65-75 \%$ carbohydrates, $5-10 \%$ protein , $15-20 \%$ dietary fibre ${ }^{[1]}$ and it shows a high antioxidant activity due to the presence of polyphenols and flavonoids ${ }^{[2]}$. Apart from the nutritional profile, millets also present various health advantages such as managing disorders like obesity, diabetes, etc ${ }^{[3]}$.

Among the millets, pearl millet and sorghum are known as the crop of food due to its nutritional significance as it contains high amount of dietary fiber, complex carbohydrates, macronutrients, and micronutrients as well as good quality photochemical ${ }^{[4]}$.

Pulses are known to be vital sources of dietary fiber, more importantly in tropical regions where there is limited consumption of animal proteins. These are already acceptable for their excellent nutritional profile which comprises of high protein content and dietary fiber along with low fat content, a good amount of phytochemicals and micronutrients are also present which also offer various health benefits ${ }^{[5]}$. Mungbean is readily known for its detoxification bioactivities and has been utilized in order to improve human mental function and mitigation of heat stroke. Generally chickpea contains moderately higher level of protein among pulses ie. $17-22 \%$, high carbohydrate content $(50 \%), 6.45 \%$ fat and $3.82 \%$ crude fiber content. The information of agricultural products on the aspects of their engineering and physical characteristics is necessary in order to align and design the suitable machinery whereas the geometric properties are considerable during the unit operations such as cleaning, separation etc ${ }^{[6]}$. The functional properties of a raw material are very important in new product development ${ }^{[5]}$. Millets and pulses have already been utilized for the preparation of nutritious extruded products ${ }^{[7]}$. Hence, the present investigation basically emphasizes on the engineering, physicochemical and functional properties of pearl millet and sorghum as well as mungbean and chickpea.

\section{Materials and Methods}

Raw material: Grains of pearl millet (PCB-164), sorghum (2077 B line), mungbean (SML832 ) and chickpea (PBG-7) of commonly cultivated varieties in Punjab, were procured from 
Directorate of Seeds of Punjab Agricultural university, Ludhiana. The samples were cleaned in order to remove any foreign materials or any damaged seeds.

Engineering properties: The engineering and geometric properties such as grain dimensions geometric mean diameter, sphericity, coefficient of external and internal friction, and true density, porosity and angle of repose were determined as per method earlier described by Kaur and coworkers ${ }^{8}$. Bulk density and 1000 kernal weight of seeds are determined as per method of Singh and coworkers ${ }^{[9]}$.

Physico-chemical properties: The contents of moisture, crude protein, total lipid and ash in the samples were determined by the standard methods of AOAC ${ }^{[10]}$. The carbohydrate content was determined as the weight difference using moisture, crude protein, crude lipid and ash content data.

Antioxidant activity: The ability of the methanolic extracts to scavenge free radicals was determined against a very stable free radical DPPH (1,1-diphenyl-2-picrylhydrazyl) determined spectrometrically as per method of earlier described by Singh and coworkers [11], Kaur and fellows ${ }^{7}$. Briefly aliquots of the sample extract at different concentrations were added to $1 \mathrm{Ml}$ methanolic solutions of DPPH. Each mixture was vortexed vigorously and left for 30 min at room temperature in the dark. The absorbance was measured at $517 \mathrm{~nm}$ and activity was expressed as percentage DPPH scavenging relative to control using the following equation:

DPPH scavenging activity $(\%)=($ Absorbance of control Absorbance of sample)/ Absorbance of control $\times 100$

Total phenolic content: The total phenolic content was determined as per FolinCiocalteu spectrophotometric method earlier described by Sharma and coworkers ${ }^{12}$, Kaur and fellows ${ }^{7}$. The results were expressed as $\mathrm{mg}$ of gallic acid equivalents (mg GAE/g dry sample).

Color Analysis: Color measurements (L*a*b*values) were done by the Hunter Lab Calorimeter. The instrument was calibrated with the user supplied black plate calibration standard that was used for zero setting. Triplicate readings were taken for each sample.

Pasting properties: A Rapid Visco Analyzer (RVA) model StarchMaster2 (Newport Scientific, Warrie Wood, Australia) was used to determine the pasting properties of millets and pulses as per standard procedure earlier discussed by Singh and coworkers ${ }^{11}$. Pasting temperature, peak viscosity, final viscosity, breakdown viscosity and Setback viscosity were recorded from the instrument.

Functional properties: The functional properties of flour from millets and legumes were determined using standard procedure. Water absorption index (WAI) and Water solubility index (WSI) were determined as per method of Anderson and coworkers ${ }^{[13]}$. Method as described by Sharma and fellows ${ }^{[14]}$ was followed to determine the oil absorption capacity (OAC) and swelling power of millets and legume flours. The results were expressed $\mathrm{g} / \mathrm{g}$. The least gelling concentration (LGC) of flours concentrates was determined according to the method described by Singh and coworkers ${ }^{[15]}$. LGC was estimated as the critical concentration below which no self-supporting gel was formed. The emulsifying properties such as emulsion activity and emulsion stability were determined by following the method of Singh and coworkers [4]. Hydrophilic/lipophilic index (HLI) was estimated as the ratio of WAC to OAC and used to define the relative affinity of flour for water and oil ${ }^{[16]}$.

\section{Results and Discussion \\ Engineering Properties}

The importance of dimensions is in determining the aperture size of machines, particularly in separation of materials. These dimensions may be useful in estimating the size of machine components as well as the organization of the processing machinery required ${ }^{[6]}$. The mean length, breadth and thickness of pearl millet grain was determined to be $3.21 \mathrm{~cm}, 1.98 \mathrm{~cm}$ and $1.89 \mathrm{~cm}$ respectively, whereas for sorghum the values are $3.79,3.66$ and 2.96 respectively. The average values of distance, breadth and thickness were found to be greater for chickpea as compared to that of mungbean, which indicates a requirement of more storage space for chickpea. The average values of GMD in case of pearlmillet, sorghum, moongbean and chickpea were found to be 2.290, $3.529,3.501$ and 6.346 respectively. The values sphericity indicate strong tendency of seed shape towards a sphere. Significance of the sphericity of the grains is to indicate the ability of the grains not to slide in the hopper, but rather to roll. This is an important factor in designing of a grain hopper as well equipment for the conveying of the grains ${ }^{[17]}$.

Density is employed for separating the materials utilizing the differences in their specific gravities. It is significant in order to design the silos and storage bins, to know the purity of grains, evaluation of maturity level of grains and the stability of feed pellets and many more ${ }^{[18]}$. Bulk densities for the grains range from $0.77-1.68 \mathrm{~g} / \mathrm{cc}$, highest being $1.68 \mathrm{~g} / \mathrm{cc}$ for chickpea, which indicates that chickpea is hardest of all the selected grains. Chickpea is followed by sorghum $(0.80 \mathrm{~g} / \mathrm{cc})$, pearl millet $(0.79)$ and mungbean $(0.77 \mathrm{~g} / \mathrm{cc})$.

The unfavorable aspects that influence the machine productivity are the frictional losses. So in order to overcome these losses, the equipment has to be provided with some extra power. But prior to all this, the frictional characteristics of the crop should be known in order to design the equipment appropriate to the crop. The values of internal and external coefficient of friction were analyzed over a wooden surface and are presented in Table 1. As per results, angle of repose was found to be maximum in case of millets ie. sorghum $\left(23.18^{\circ}\right)$ followed by pearl millet $\left(19.40^{\circ}\right)$. For pulses, angle of repose for chickpea was $19.09^{\circ}$ followed by mungbean $\left(18.45^{\circ}\right)$. More porosity signifies better heat exchange or better cooling, thus effective and uniform processing. Highest porosity was found in case of chickpea (36.80) followed by that of mungbean (35.11), which may be due to the larger size of chickpea.

\section{Physicochemical Properties}

Proximate composition of studied grains is given in table 2 . Protein content was found to be the highest in case of chickpea $(24.59 \%)$ followed by mungbean $(22.44)$. In case of millets, Pearl millet presented higher protein content $(12.15 \%)$ than that of sorghum $(9.69 \%)$. Fat content was highest in case of pearl millet $(4.10 \%)$ and was minimum for chickpea $(1.17 \%)$, whereas mungbean exhibited highest ash content $(3.07 \%)$ and highest fiber Content (5.22). Results were in agreement with the study by Kaur and Singh [19], where different varieties of chickpea were analyzed for their 
properties and composition. Protein content was found to be in the range of $20.6-26.7 \%$ in different chickpea varieties. Other values are also found in the same range. Similar results were presented by $\mathrm{Du}$ and coworkers [20], where the physicochemical and functional properties of whole legume flours were analyzed. Few variations in the chemical composition as compared to the previous studies can be attributed to the genetic differences and the environmental differences ${ }^{[20]}$. In case of sorghum, the results were similar to that of Adeyeye ${ }^{[21]}$, where it was indicated that higher values of fat and fiber are because of whole grains, as de-hulling was not done.

\section{Functional properties}

Water absorption Index is basically associated with the macromolecules (starch, protein) present in the flour that signifies the properties like gelation activity and hydrophilicity ${ }^{[19]}$. In case of legumes, WAI was found to be higher for Mungbean $(8.139 \mathrm{~g} / \mathrm{g})$ as compared to that of chickpea $(5.267 \mathrm{~g} / \mathrm{g})$. Whereas for millets, it was found to be higher for sorghum $(6.742 \mathrm{~g} / \mathrm{g})$ than that of pearlmillet $(4.904$ $\mathrm{g} / \mathrm{g})$. An increase in WAI might be due to protein denaturation caused by heating during milling of the flour, starch granule destruction and gelatinization and crude fiber water swelling [22].

Water solubility Index is related to the content of soluble substances in the flour, which is different for different flours. WSI of pearlmillet, sorghum, mungbean and chickpea was found to be $8.31,11.46,7.49$ and $11.07 \%$ respectively. WSI is reported to be affected by the amylase-lipd and protein starch complexes formed because of heating (while milling in this case) ${ }^{[23]}$

Oil absorption is basically the function of hydrophobic proteins, which have non polar amino acid chains that binds with the paraffin chains of fats ${ }^{24}$. It was found to be higher for chickpea $(122 \%)$ for legumes, sorghum (126\%) in case of millets. The OACs of different legume flours are influenced by particle sizes, starch and protein contents, protein types and non-polar amino acid side chain ratios on the protein molecule surface ${ }^{[23]}$.

Due to interfacial tension, there is a lot of free energy available in an emulsion of water and fat, thus rendering it unstable thermodynamically. Thus emulsifiers are used that stabilize the emulsions by creating a thin layer at the interface of fat and water,that lowers the interfacial tension [24]. Emulsion activity and stability was found to be higher in case of mungbean $(65.82 \%$ and $85.01 \%)$ followed by chickpea $(59.43 \%, 83.07 \%)$ and then for millets.

\section{In vitro protein digestibility, Antioxidant properties and Total phenolic content}

Since absorption of food proteins is of paramount importance, in vitro protein digestibility of crops was also analyzed. The presence of different types of bioactive compounds, structural characteristics etc may influence the IVPD values. Here IVPD of chickpea was found to be significantly higher $(62.2 \%)$ as compared to mungbean $(52 \%)$ whereas in millets the values are $52.08 \%$ and $45.77 \%$. The legume results were comparable to that of Ratnawati and coworkers, where a significant difference was seen in IVPD values of legumes and were in in the range of $33.36-80.54 \%{ }^{[25]}$.

In the present study, total phenolic content for mungbean and chickpea are $1.8804 \mathrm{mg}$ GAE/g and $1.8508 \mathrm{mg} \mathrm{GAE} / \mathrm{g}$ respectively. The results are in accordance with Marathe and coworkers, where the TPC values for legumes were in the range of $0.325-6.378 \mathrm{mg} \mathrm{GAE} / \mathrm{g}$. It has been mentioned that the outer layers of the seed are associated with the presence of higher polyphenolic compounds ${ }^{[26]}$. Although the variations associated with particular legume is related to the genetic factors, environmental conditions and degree of maturity.

Antioxidants are associated with many health benefits such as management of diseases that are age-related, reducing the harmful effects of toxicity causing agents and thus maintaining the health ${ }^{[27]}$. Antioxidant activity was found to be higher for pearlmillet $(30.08 \%)$ followed by that of sorghum (29\%). In case of legumes, higher amount was seen in chickpea a $(24.82 \%)$ as compared to that of mungbean $(12.8 \%)$. The phytochemicals in millet, such as phenolics and dietary fiber, were predominantly posited in the bran layers, together with micronutrients (carotenoids and tocopherols) known to have antioxidant properties ${ }^{28}$. Legumes contain varied amounts of polyphenols and possess wide range of antioxidant activity. Dark color legumes are known to have a higher antioxidant activity ${ }^{[26]}$.

\section{Color characteristics and Pasting properties}

Color was analyzed for flours using colorimeter. $\mathrm{L}^{*}, \mathrm{a}^{*}$ and $b^{*}$ values were examined (Table 4$)$. The value of $\mathrm{L}^{*}$ was more for sorghum and chickpea as the flour was lighter as compared to mungbean and pearl millet. Value of $b^{*}$ was more for mungbean because the color of flour was more towards yellowness, followed by that of chickpea. Whereas the value of $\mathrm{a}^{*}$ was more for pearl millet as the color of flour was more towards redness. Pasting properties of millets and pulses is given in Table 5. If we compare the results with that of $\mathrm{Du}$ and coworkers, who analyzed the functional properties of whole legume flours, the values have shown quite a variation, which may be due to the genetic differences and differences in the composition of these flours, that may vary with the regions of production. However Du and coworkers mentioned that chickpea has shown lowest values for pasting viscosity as compared to other legume flours. Here in this study if we compare chickpea and mungbean, similar results could be seen, however overall the values are higher than Du and coworkers, low breakdown viscosity of chickpea may be due to higher fat content, which may restrict the starch swelling ${ }^{[20]}$. Whereas the pasting properties of pearl millet are significantly different from that of literature, which may be due to the varietal differences as well as due to presence of outer covering ${ }^{[29]}$. The pasting viscosity of sorghum flour was in accordance to Chanapamokkhot and Thongngam ${ }^{[30]}$, where it was found to be lower than that of starches, may be because the protein presence in flour could inhibit swelling of starch granules. 
Table 1: Engineering properties of pearlmillet, sorghum, mungbean and chickpea.

\begin{tabular}{|c|c|c|c|c|}
\hline Physical properties & Pearl millet & Sorghum & Mungbean & Chickpea \\
\hline Length (mm) & $3.21 \pm 0.01$ & $3.79 \pm 0.02$ & $4.18 \pm 0.03$ & $7.58 \pm 0.04$ \\
\hline Breadth (mm) & $1.98 \pm 0.01$ & $3.66 \pm 0.03$ & $3.17 \pm 0.02$ & $5.90 \pm 0.03$ \\
\hline Thickness (mm) & $1.89 \pm 0.02$ & $3.17 \pm 0.01$ & $3.24 \pm 0.03$ & $5.72 \pm 0.04$ \\
\hline Geometrical mean diameter & $2.29 \pm 0.01$ & $3.52 \pm 0.02$ & $3.501 \pm 0.03$ & $6.346 \pm 0.06$ \\
\hline Sphericity & $0.69 \pm 0.01$ & $0.90 \pm 0.02$ & $0.84 \pm 0.02$ & $0.83 \pm 0.02$ \\
\hline Coefficient of internal friction (g/g) & $0.282 \pm 0.02$ & $0.23 \pm 0.02$ & $0.31 \pm 0.12$ & $0.33 \pm 0.15$ \\
\hline Coefficient of ExternalFriction(g/g) & $0.51 \pm 0.02$ & $0.48 \pm 0.02$ & $0.53 \pm 0.14$ & $0.59 \pm 0.18$ \\
\hline Bulk density ( g/cc) & $0.79 \pm 0.03$ & $0.80 \pm 0.02$ & $0.77 \pm 0.03$ & $1.68 \pm 0.03$ \\
\hline True density (g/cc) & $1.25 \pm 0.05$ & $1.44 \pm 0.03$ & $1.31 \pm 0.03$ & $1.42 \pm 0.02$ \\
\hline Angle of repose (degrees) & $19.40 \pm 1.05$ & $23.18 \pm 1.66$ & $18.45 \pm 2.45$ & $19.09 \pm 2.33$ \\
\hline Porosity (\%) & 36.8 & 29.6 & 35.11 & 18.30 \\
\hline Thousand gram seed weight(g) & $11.19 \pm 2.11$ & $33.19 \pm 1.45$ & $38.6 \pm 2.11$ & $46.77 \pm 1.00$ \\
\hline
\end{tabular}

Table 2: Proximate composition of pearlmillet, sorghum, mungbean and chickpea.

\begin{tabular}{|c|c|c|c|c|c|}
\hline & Protein (\%) & Fat (\%) & Ash (\%) & Fiber (\%) & Carbohydrates (\%) \\
\hline Pearl millet & $12.15 \pm 0.75$ & $3.11 \pm 0.12$ & $1.54 \pm 0.22$ & $3.16 \pm 0.17$ & $77.42 \pm 1.88$ \\
\hline Sorghum & $9.69 \pm 0.17$ & $3.23 \pm 0.13$ & $1.82 \pm 0.07$ & $3.35 \pm 0.22$ & $74.08 \pm 0.73$ \\
\hline Mungbean & $22.44 \pm 0.24$ & $1.21 \pm 0.11$ & $3.07 \pm 0.13$ & $5.22 \pm 0.17$ & $60.88 \pm 1.23$ \\
\hline Chickpea & $24.59 \pm 0.93$ & $4.36 \pm 0.21$ & $2.58 \pm 0.11$ & $1.89 \pm 0.32$ & $66.55 \pm 1.11$ \\
\hline
\end{tabular}

Table 3: Functional properties of pearlmillet, sorghum, mungbean and chickpea.

\begin{tabular}{|c|c|c|c|c|}
\hline & Pearl millet & Sorghum & Mungbean & Chickpea \\
\hline WAI (g/g) & $4.904 \pm 0.04$ & $6.742 \pm 0.05$ & $8.139 \pm 0.04$ & $5.267 \pm 0.01$ \\
\hline WSI (\%) & $8.31 \pm 0.05$ & $11.46 \pm 0.03$ & $7.49 \pm 0.04$ & $11.07 \pm 0.48$ \\
\hline Swelling power & $6.224 \pm 0.07$ & $7.42 \pm 0.07$ & $3.874 \pm 0.04$ & $5.53 \pm 0.06$ \\
\hline OAC (\%) & $116.33 \pm 4.50$ & $126 \pm 4.33$ & $111 \pm 9.89$ & $122 \pm 5.88$ \\
\hline Hydrophilic lipophilic index & $1.123 \pm 0.04$ & $1.0 \pm 0.05$ & $1.909 \pm 0.04$ & $0.939 \pm 0.05$ \\
\hline Emulsion activity (\%) & $44.66 \pm 0.57$ & $50.40 \pm 0.44$ & $65.82 \pm 0.88$ & $59.43 \pm 0.64$ \\
\hline Emulsion stability (\%) & $49.3 \pm 1.33$ & $56.6 \pm 1.15$ & $85.01 \pm 1.41$ & $83.07 \pm 1.70$ \\
\hline IVPD (\%) & $52.08 \pm 0.04$ & $45.77 \pm 0.05$ & $53.33 \pm 0.02$ & $62.2 \pm 0.04$ \\
\hline Antioxidant activity (\%) & $30.08 \pm 0.11$ & $29 \pm 0.15$ & $12.8 \pm 1.09$ & $24.82 \pm 0.22$ \\
\hline TPC (gm GAE/g) & $3.0918 \pm 0.27$ & $2.221 \pm 0.55$ & $1.8804 \pm 0.39$ & $1.8508 \pm 0.49$ \\
\hline
\end{tabular}

Table 4: Color characteristics of the flours.

\begin{tabular}{|c|c|c|c|}
\hline & $\mathbf{L}^{*}$ & $\mathbf{a}^{*}$ & $\mathbf{b}^{*}$ \\
\hline BAJRA & $62.33 \pm 0.15$ & $2.26 \pm 0.14$ & $8.7 \pm 1.42$ \\
\hline MOONGBEAN & $63.17 \pm 1.34$ & $0.12 \pm 0.22$ & $19.93 \pm 2.11$ \\
\hline SORGHUM & $81.82 \pm 2.02$ & $1.42 \pm 0.16$ & $11.09 \pm 0.05$ \\
\hline CHICKPEA & $88.72 \pm 0.13$ & $-0.4 \pm 0.05$ & $15.48 \pm 0.12$ \\
\hline
\end{tabular}

Table 5: Pasting profiles of the flours.

\begin{tabular}{|c|c|c|c|c|}
\hline & Pearl millet & Mungbean & Sorghum & Chickpea \\
\hline Peak Temperature & $70.6 \pm 2.2$ & $78.4 \pm 1.1$ & $95.6 \pm 3.2$ & $77.8 \pm 0.7$ \\
\hline Peak viscosity & $99 \pm 7.6$ & $207 \pm 6.3$ & $341 \pm 4.1$ & $98.2 \pm 1.9$ \\
\hline Hold viscosity & $96 \pm 3.4$ & $135.4 \pm 0.9$ & $332 \pm 1.2$ & $93.3 \pm 2.3$ \\
\hline Final viscosity & $863 \pm 5.8$ & $233.8 \pm 2.8$ & $1498 \pm 4.5$ & $123.8 \pm 2.2$ \\
\hline Breakdown viscosity & $3 \pm 1.8$ & $71.6 \pm 4.4$ & $9 \pm 3.3$ & $4.9 \pm 0.5$ \\
\hline Setback viscosity & $767 \pm 2.2$ & $98.4 \pm 1.7$ & $1166 \pm 4.7$ & $30.5 \pm 0.2$ \\
\hline
\end{tabular}

\section{Conclusion}

As consumption of wholegrain flour products is in trend these days, therefore, the information on engineering, physicochemical and functional properties of these millets and legumes will be helpful in opening newer options for research. Phenolic compounds and rich antioxidant property of pearlmillet and sorghum, whereas protein content and quality of pulses could be utilized. These properties could be considered while incorporating these raw materials for preparation of complementary food products.

\section{References}

1. Devisetti R, Yadahally SN, Bhattacharya S. Nutrients and antinutrients in foxtail and proso millet milled fractions:
Evaluation of their flour functionality. Lwt-Food Sci Technol. 2014; 59(2):889-95.

2. Chandrasekara A, Naczk M, Shahidi F. Effect of processing on the antioxidant activity of millet grains. Food Chem. 2012; 133(1):1-9.

3. Jaybhaye RV, Pardeshi IL, Vengaiah PC, Srivastav PP. Processing and Technology for miller based food products: A review. J Ready eat food. 2014; 1(2):32-48.

4. Singh A, Sharma S, Singh B. Influence of grain activation conditions on functional characteristics of brown rice flour. Food Sci. Technol. Int. 2017a; 23:500512.

5. Singh A, Sharma S. Bioactive components and functional properties of biologically activated cereal grains: a 
bibliographic review. Crit. Rev. Food Sci. Nutr. 2017; 57:3051-3071.

6. Ghamari S, Mohammadi K, Khanahmadzadeh A and Goli H. Evaluation the some physical properties of chickpea seeds in Kurdistan Region of Iran. Int $\mathbf{J}$ Agri Forestry. 2014; 4(3A): 4.

7. Kaur J, Singh B, Singh A, Sharma S. Characterization of extruded products from millets-legumes in combinations. Pharma Innov J. 2020; 9(4):369-374.

8. Kaur M, Kaur P, Kaur A. Engineering properties of peeled and unpeeled garlic cloves. Agric Res J. 2017; 54(1):85-89.

9. Singh A, Sharma S, Singh B. Germination behaviour, physico-nutritional properties, and diastase activity of brown rice influenced by germination time and temperature. Acta Alimen. 2018; 47:70-79.

10. AOAC. Official Methods of Analysis. 17th Edition, The Association of Official Analytical Chemists, Gaithersburg, MD, USA, 2000

11. Singh A, Sharma S, Singh B, Kaur G. In vitro nutrient digestibility and antioxidative properties of flour prepared from sorghum germinated at different conditions. J Food Sci. Technol. 2019; 56:3077-3089.

12. Sharma S, Singh A, Singh B. Characterization of in vitro antioxidant activity, bioactive components, and nutrient digestibility in pigeon pea as influenced by germination time and temperature. J Food Biochem. 2019a; 43(2):e12706.

13. Anderson RA, Conway HF, Pfeifer VF, Griffin EL. Gelatinization of corn grits by roll- and extrusioncooking. Cereal Science Today. 1969; 14:4-12.

14. Sharma S, Singh A, Singh B. Effect on germination time and temperature on techno-functional properties and protein solubility of pigeon pea (Cajanus cajan) flour. Quality Assurance and Safety of Crops \& Foods. 2019b; 11(3):305-312.

15. Singh A, Sharma S, Singh B. Effect of germination time and temperature on the functionality and protein solubility of sorghum flour. Journal of Cereal Science. 2017b; 76:131-139.

16. Coulibaly A, Kouakou B, Chen J. Extruded Adult Breakfast Based on Millet and Soybean: Nutritional and Functional Qualities, Source of Low Glycemic Food. J Nutr Food Sci. 2012; 2:7.

17. Gana IM, Agidi G, Idah PA, Anounye JC. Influence of soaking on moisture-dependent physical properties of some selected grains essential to design of grain drinks processing machine. Agric Sci Dev. 2014; 3(7):237-243.

18. Chhabra N, Kaur A. Studies on physical and engineering characteristics of maize, pearl millet and soybean. Int $\mathbf{J}$ Pharmacogn Phytochem. 2017; 6(6):01-06.

19. Kaur M, Singh N. Studies on functional, thermal and pasting properties of flours from different chickpea (Cicer arietinum L.) cultivars. Food Chem 2005; 91:403411.

20. Du SK, Jiang X, Yu X, Jane J. Physicochemical and functional properties of whole legume flour. LWT-Food Science and Technology 2013, 1-6.

21. Adeyeye SAO. Assessment of quality and sensory properties of sorghum-wheat flour cookies. Cogent Food Agric 2016; 2(1): 1245059.

22. Milán-Carrillo J, Reyes-Moreno C, Armienta-Rodelo E, et al. Physicochemical and nutritional characteristics of extruded flours from fresh and hardened chickpeas (Cicer arietinum L.) LWT: Food Sci Technol. 2000; 33:117123.

23. Duodu KG, Nunes A, Delgadillo I, Belton PS. Low protein digestibility of cooked sorghum- causes and needs for further research, 2014.

24. Kinsella JE. Functional properties of soy proteins. J Am Oil chemists soc 1979; 56(4):242-258.

25. Ratnawati L, Desnilasari D, Surahman DN, Kumalasari R. Evaluation of physicochemical, functional and pasting properties of soybean, mungbean and red kidney bean flour as ingredient in biscuit. IOP Conf. Series: Earth and Environmental Science. 2019; 251:01 2026.

26. Marathe SA, Rajalakshmi V, Jamdar SN, Sharma A. Comparative study on antioxidant activity of different varieties of commonly consumed legumes in India. Food and Chemical Toxicology. 2011; 49:2005-2012.

27. Mishra K, Ojha H, Chaudhury NK. Estimation of antiradical properties of antioxidants using DPPH assay: A critical review and results. Food Chemistry. 2012; 130(4):1036-1043.

28. Liang S, Liang K. Millet grain as a candidate antioxidant food resource: a review, International J Food Prop, 2019; 22:1652-1661DOI: 10.1080/10942912.2019.1668406.

29. Eke-Ejiofer J, Oparaodu FO. Chemical, functional and pasting properties of flours of three millet varieties. Res J Food Nutr. 2019; 3(3):15-21.

30. Chanapamokkhot H, Thongngam $M$. The chemical and physic-chemical properties of sorghum starch and flour. Kasetsart J (Nat. Sci.). 2007; 41:343-349. 